\title{
Evaluating SWAT Snowmelt Parameters and Simulating Spring Snowmelt Nonpoint Source Pollution in the Source Area of the Liao River
}

\author{
Yu Wang ${ }^{1}$, Jianmin Bian ${ }^{1 *}$, Sining Wang ${ }^{1}$, Jie Tang ${ }^{1}$, Fei Ding ${ }^{2}$ \\ ${ }^{1}$ Key Lab of Groundwater Resources and Environment, Jilin Province, College of the Environment and Resources, \\ Jilin University, Changchun 130021, China \\ ${ }^{2}$ Key Laboratory of Beijing for Water Quality Science and Water Environment Recovery Engineering, \\ College of Architecture and Civil Engineering, \\ Beijing University of Technology, Beijing 100000, China
}

Received: 22 March 2016

Accepted: 14 May 2016

\begin{abstract}
Snowmelt hydrology becomes an important component of the soil and water assessment tool (SWAT) when spring flows are dominated by melting snow. The objective of this study was to evaluate the performance of the SWAT model's snowmelt parameters by simulating nonpoint source pollution in the source area of the Liao River - a cold area in China. The seven snowmelt parameters for the simulation were adjusted. The exports rule of nonpoint source pollution for the spring snowmelt period was analyzed. The result show that SFTMP, SMTMP, SMFMX, SMFMN, and TIMP were sensitive parameters, while SNOCOVMX and SNO50COV were insensitive. In addition, two common statistics (Nash-Sutcliffe coefficient, and coefficient of determination) were used to evaluate the model. This evaluation indicated that the SWAT model had good performance simulating the seasonal nonpoint source pollution with large snowmelt. According to the analysis, rainfall and snowmelt is a main driver of nonpoint source pollution in the cold area, and that summer and spring are high-risk seasons. The study provides a new and suitable method of nonpoint source pollution simulation for the cold areas.
\end{abstract}

Keywords: SWAT, snowmelt parameters, sensitivity analysis, nonpoint source pollution

\section{Introduction}

Nonpoint source pollution (NPS) is of increasingly great concern due to its adverse impacts on receiving waters and the resulting impact on society. Nonpoint

*e-mail: bianjianmin@126.com source pollution may derive from many different sources, making it difficult to control and regulate [1]. The U.S. Environmental Protection Agency (USEPA) has determined that NPS is the primary cause of water pollution in the United States today [2]. In China, agricultural nonpoint source pollution has contributed more than point source pollution, largely due to the Beijing Miyun and Tianjin Yuqiao reservoirs, which are the main cause of 
water pollution [3-5]. Therefore, a quantitative assessment of nonpoint source pollution load is particularly urgent, and research on agricultural nonpoint source pollution simulation is an important way to solve this problem.

Nonpoint source pollution models include the empirical statistical model and distributed model [6]. The mpirical statistical model is characterized by its simple structure and less demand for original data. However, the model ignores the pollutant migration mechanism of complex processes. The distributed model is based on the pollution process mechanism, which mainly consists of rainfall runoff, soil erosion, and pollutant output, and it has robust simulation ability [7]. The soil and water assessment tool (SWAT), developed at the United States Department of Agriculture [8], is a physically based, spatially distributed simulation of the hydrologic cycle and pollutant mobilization and transport at a catchment scale. SWAT has been widely used to predict the impact of management practices on water, sediment, and agricultural chemical yields in large complex watersheds over extended periods of time [9-10]. The vast majority of SWAT evaluations were conducted in rainfall-runoff-dominant watersheds, with negligible contributions from snowmelt (especially in cold areas).

Although some researchers [11-13] have pointed out that the snowmelt process is an important component, there is a lack of information regarding SWAT's performance in snow-covered catchments where stream flows are predominantly generated from spring snowmelt. In a study designed to address this issue, Peterson and Hamlet underlined SWAT's difficulty in low-flow prediction during snowmelt events (as the snowmelt routine in SWAT was based on the temperature-index approach with a constant snowmelt rate factor) [14]. Fontaine modified the snowmelt hydrology algorithm by changing the model architecture. The major refinements of snowmelt processes include spatial coverage evaluation bands of the snowpack, the seasonal variation of the snowmelt rate, and the effects of elevation on snowmelt estimation procedure by defining up to 10 elevations in each sub-basin [15]. These new developments have promoted the use of SWAT in snowy catchments.

Snowmelt and rainfall runoff are two different kinds of hydrological processes that influence the migration of nonpoint source pollution simultaneously. Compared with the rainfall runoff process, snowmelt is a slow and gradual process, and it is treated as rainfall with zero energy in SWAT [16]. Therefore, it is important to set up a SWAT model to predict nonpoint source pollution from these two processes with acceptable accuracy.

The source area of the Liao River, which is an important grain-growing area in China, experiences serious problems with agricultural nonpoint source pollution that impact the regional economy and society. The watershed is located in China's northeastern cold region where winters are long and hard, with snow for six months of the year. Spring snowmelt runoff on soil erosion is obvious, and unique climate conditions lead particularly to nonpoint source pollution [17]. In this paper we used SWAT to establish the snowmelt model of nonpoint source pollution in the Liao source area, and sensitivity analysis was carried out on the snowmelt parameters to determine the optimum value range of parameters. Simultaneously, the exports rule of agricultural nonpoint source pollution in the spring snowmelt period was analyzed.

\section{Study Area and Data Source}

\section{Study Area}

The Liao source area is located in southwestern Jilin Province $\left(123^{\circ} 31^{\prime} \sim 125^{\circ} 42^{\prime} \mathrm{E}, 34^{\prime} 44^{\circ} \sim 42^{\circ} 08^{\prime} \mathrm{N}\right)$, a typical cold area in northeastern China (Fig. 1). This source area covers the Liao River basin, the Zhaosutai River basin, and the Tiaozi River basin. The study area has a temperate continental monsoon climate, and annual average temperature is $4-6^{\circ} \mathrm{C}$ with the lowest value of $-14.8^{\circ} \mathrm{C}$ in January and the highest of $23.6^{\circ} \mathrm{C}$ in July. The annual average sunshine time is about 2,800 hours, the frost-free period is about 120-150 days, and maximum frozen soil depth is $148 \mathrm{~cm}$. Average annual precipitation is $545 \mathrm{~mm}$, with approximately $80 \%$ of the annual precipitation falling during June, July, August, and September [18].

Agricultural activity in the area is prevalent, with corn and rice being the main crops. The land use types are mainly farmland. The descending order of the land use area is dry fields, woodlands, towns, paddy fields, and grassland (at $62.66 \%, 16.92 \%, 8.73 \%, 5.24 \%$, and $1.91 \%$, respectively; others are less than 5\%). Precipitation demonstrates uneven spatial and temporal distribution so that precipitation alone cannot meet the demands of the crops, which still rely on irrigation. During the farming period, along with the leaching effect of precipitation and irrigation, nitrogen and phosphorus pollutants in fertilizers migrate from soil to the surface water and groundwater, causing deterioration of water quality. At present, the water quality monitoring data in the three main streams indicate that nonpoint source pollutant nitrogen and phosphorus both exceeded water quality standards (class III) [19]. Agricultural activities have become the main components of nonpoint source pollution in the Liao River source area.

\section{Input Data and Processing}

The digital elevation model (DEM) used in this study was obtained from the international scientific data service platform (wist.echo.nasa.gov), which provides digital elevation data at $90 \mathrm{~m} \times 90 \mathrm{~m}$ resolution. The DEM was used to delineate the watersheds and to analyze the drainage patterns within the study area.

The types and spatial distribution of land use were obtained from Landsat thematic mapper and enhanced thematic mapper image data mosaics acquired in 2008 using geometric corrections, image enhancement, cutting, and preprocessing using Erdas 9.0. The soil data was obtained from the second soil survey in Jilin Province and 


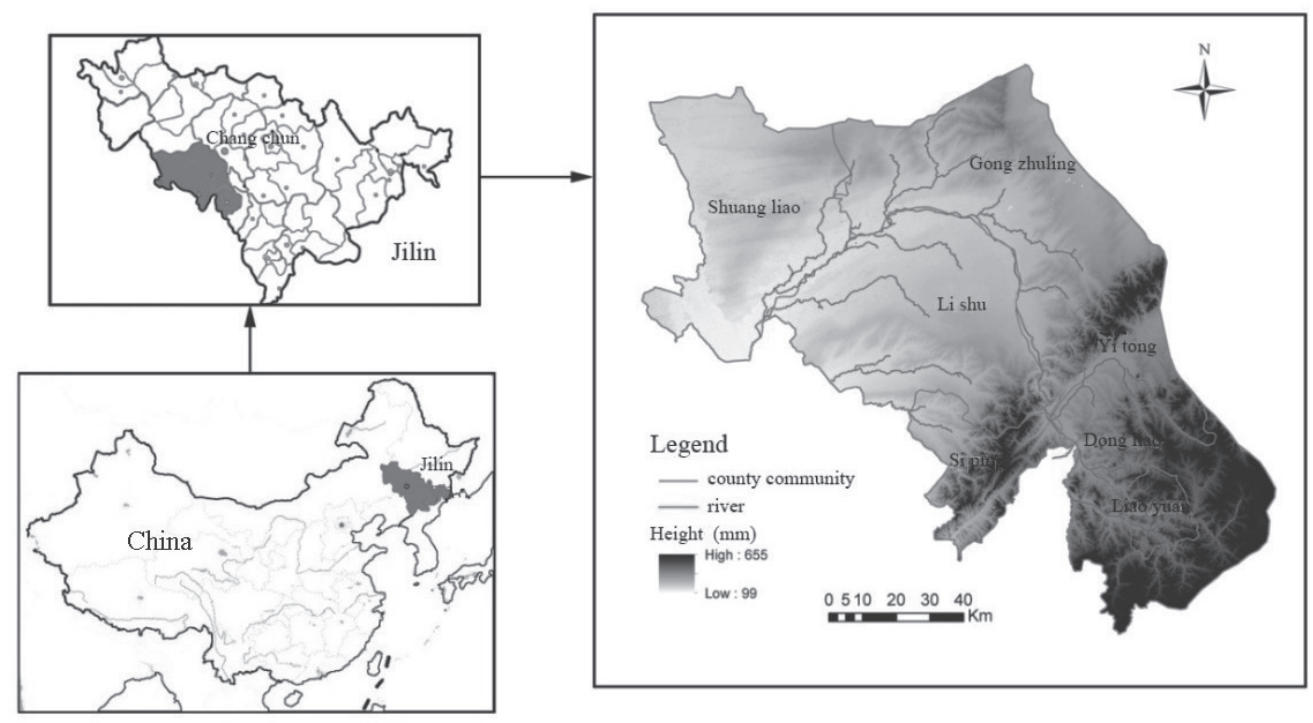

Fig. 1. Location map and DEM in the study area.

processed using the same steps that were followed when preparing land use maps.

The model is run using daily precipitation, maximum/ minimum temperatures, solar radiation, wind speed, and relative humidity input from observed data or generated during simulation. Meteorological data from eight stations was obtained from the China Meteorological data sharing service network (cdc.cma.gov.cn/home.do) and/or the Siping City Bureau of Hydrology. The meteorological stations were located at Changchun, Siping, Shuangliao, Liaoyuan, Quantai, Erlongshan Reservoir, Wangben, and Lishu. The period of record was from 2000 to 2010.

This paper uses two statistical indexes to evaluate the accuracy of the model. The Nash-Sutcliffe efficiency coefficient NS and the correlation coefficient $\mathrm{R}^{2}$ are defined as follows:

$$
\begin{gathered}
N S=1-\frac{\sum_{i=1}^{n}\left(Q_{o}-Q_{p}\right)^{2}}{\sum_{i=1}^{n}\left(Q_{o}-\overline{Q_{o}}\right)^{2}} \\
R^{2}=\frac{\left[\sum_{i=1}^{n}\left(Q_{p, i}-\overline{Q_{p}}\right)\left(Q_{o, i}-\overline{Q_{o}}\right)\right]^{2}}{\sum_{i=1}^{n}\left(Q_{o, i}-\overline{Q_{o}}\right)^{2} \sum_{i=1}^{n}\left(Q_{p, i}-\overline{Q_{p}}\right)^{2}}
\end{gathered}
$$

...where $Q_{p}$ is the predicted value, $Q_{o}$ is measured value, $\bar{Q}_{p}$ is mean predicted value, $\bar{Q}_{o}$ is mean measured value, and $n$ is the number of observations.

\section{Study Method}

The SWAT model was developed by the U.S. Agricultural Research Service Center in the 1990s. The model was improved by Fontaine in 2002 by increasing the snow melting module and extending the application of the SWAT model to the cold regions from the south to the north [20]. Generally speaking, in cold regions there is a long winter each year from the end of October to early November called the freezing period, which continues until the next year to the end of March. The freeze-thaw period takes about five months, occupying almost half the year. Climate characteristic of the freeze-thaw process and snowmelt effects results in special environmental behavior of nonpoint source pollution. Therefore, it is necessary to increase snowmelt simulation to improve model accuracy and thereby reduce model uncertainty.

\section{SWAT Snow Melting Module Principle}

At present, the SWAT snow melting module uses the method of degree day factor, and the degree of the factor is the sine function with the time variation. The SWAT model can divide precipitation as snow or rain, according to the set of snow-critical temperatures. When snow exists in a sub-basin field, then the snowmelt simulation can be conducted. When the set of snowfall critical temperatures is lower than the threshold value, we close the snowmelt module [21]. The snowpack increases with additional snowfall, but decreases with snowmelt or sublimation [22]. The mass balance for the snowpack is computed as:

$$
\mathrm{SNO}_{i}=\mathrm{SNO}_{i-1}+\mathrm{R}_{\mathrm{sfi}}-\mathrm{E}_{\mathrm{subi}}-\mathrm{SNO}_{\mathrm{mlti}}
$$

...where $\mathrm{SNO}_{i}$ and $\mathrm{SNO}_{i-1}$ are the water equivalents of the snowpack on the current day $(i)$ and precious day $(i-1)$, respectively, $\mathrm{R}_{\mathrm{sfi}}$ is the water equivalent of the snow precipitation on day $i, \mathrm{E}_{\text {sub } i}$ is the water equivalent of some sublimation on day $i$, and $\mathrm{SNO}_{\mathrm{mlt}}$ is the water equivalent of the snowmelt on day $i$. All of these variables are reported in terms of equivalent water depth $(\mathrm{mm})$ over the total area. 
The snowpack is rarely uniformly distributed over the total area, resulting in a fraction of the area that is bare of snow. The model using the snow area deletion curve calculates the coverage of snow over the total area, and is defined as:

$$
\begin{aligned}
& \mathrm{SNO}_{\mathrm{cov} i}=\frac{\mathrm{SNO}_{i}}{\mathrm{SNOCOVMX}}\left[\frac{\mathrm{SNO}_{i}}{\mathrm{SNOCOVMX}}+\right. \\
& \left.+\exp \left(\operatorname{cov}_{1}-\operatorname{cov}_{2} \cdot \frac{\mathrm{SNO}_{i}}{\mathrm{SNOCOVMX}}\right)\right]^{-1}
\end{aligned}
$$

...where $\mathrm{SNO}_{\text {covi }}$ is the fraction of the area covered by snow on the current day $(i)$, SNOCOVMX is the minimum snow water content that corresponds to $100 \%$ snow cover $\left(\mathrm{mm} \mathrm{H}_{2} \mathrm{O}\right.$ ), and $\operatorname{cov}_{1}$ and $\operatorname{cov}_{2}$ are the coefficients that define the shape of the curve.

When calculating snowmelt we calculate the difference between the mean temperature of snowpack and the snowmelt temperature threshold with the equation:

$$
\mathrm{SNO}_{\mathrm{mlt} i}=\mathrm{b}_{\mathrm{mlt} i} \cdot \mathrm{SNO}_{\mathrm{cov} i}\left(\frac{\mathrm{T}_{\mathrm{sp} i}+\mathrm{T}_{\max i}}{2}-\mathrm{SMTMP}\right)
$$

...where $\mathrm{SNO}_{\text {mlti }}$ is the amount of snowmelt on the current day ( $i$, expressed in terms of the equivalent amount of water in $\mathrm{mm}), \mathrm{T}_{\max i}$ is the maximum air temperature on day $i\left({ }^{\circ} \mathrm{C}\right)$, SMTMP is the base temperature above which snowmelt is allowed $\left({ }^{\circ} \mathrm{C}\right)$, and $\mathrm{b}_{\text {mlti }}$ is the melt factor on day $i\left(\mathrm{~mm} \mathrm{H}_{2} \mathrm{O}^{\circ} \mathrm{C}^{-1} \cdot \mathrm{d}^{-1}\right)$, which is calculated as:

$$
\begin{gathered}
\mathrm{b}_{\mathrm{mlt} i}=\frac{\text { SMFMX }+ \text { SMFMN }}{2}+\frac{\text { SMFMX-SMFMN }}{2} . \\
\cdot \sin \left[\frac{2 \pi}{365}(i-81)\right]
\end{gathered}
$$

...where SMFMX and SMFMN are the maximum and minimum snowmelt factors, respectively $(\mathrm{mm}$ $\left.\mathrm{H}_{2} \mathrm{O}^{\circ} \mathrm{C}^{-1} \cdot \mathrm{d}^{-1}\right)$.

The snowpack temperature is calculated as:

$$
\mathrm{T}_{\mathrm{sp} i}=\mathrm{T}_{\mathrm{sp} i-1}(1-\mathrm{TIMP})+\mathrm{T}_{\mathrm{a} i} \mathrm{TIMP}
$$

...where TIMP is the snow temperature hysteresis factor that implicitly accounts for snowpack density, water content, and exposure; $\mathrm{T}_{\mathrm{sp} i}$ and $\mathrm{T}_{\mathrm{sp} i-1}$ are the snowpack temperature on the current day $(i)$ and the previous day $(i-1)$; and $\mathrm{T}_{\mathrm{a} i}$ is the mean air temperature on day $i$.

\section{Snowmelt Parameter Sensitivity Analysis}

The seven snowmelt parameters (SFTMP, SMTMP, SMFMX, SMFMN, TIMP, SNOCOVMX, and SNO50COV) discussed in the section on SWAT snowmelt

\begin{tabular}{|c|c|c|c|}
\hline $\begin{array}{l}\text { Snowmelt } \\
\text { Parameter }\end{array}$ & Name & Range & Sensitive \\
\hline SMFMX & $\begin{array}{l}\text { Maximum snowmelt } \\
\text { factor } \\
\left(\mathrm{mm} \mathrm{H}_{2} \mathrm{O}^{\circ} \mathrm{C}^{-1} \cdot \mathrm{d}^{-1}\right)\end{array}$ & $0-20$ & Yes \\
\hline SMFMN & $\begin{array}{l}\text { Minimum snowmelt } \\
\text { factor } \\
\left(\mathrm{mm} \mathrm{H}_{2} \mathrm{O}^{\circ} \mathrm{C}^{-1} \cdot \mathrm{d}^{-1}\right)\end{array}$ & $0-20$ & Yes \\
\hline SMTMP & $\begin{array}{c}\text { Snowmelt temperature } \\
\left({ }^{\circ} \mathrm{C}\right)\end{array}$ & $-20-20$ & Yes \\
\hline SFTMP & $\begin{array}{l}\text { Snowfall temperature } \\
\qquad\left({ }^{\circ} \mathrm{C}\right)\end{array}$ & $-20-20$ & Yes \\
\hline TIMP & $\begin{array}{c}\text { Snowpack temperature } \\
\text { gag factor }\end{array}$ & $0-1$ & Yes \\
\hline SNOCOVMX & $\begin{array}{c}\text { Minimum snow } \\
\text { water content that } \\
\text { corresponds to } 100 \% \\
\text { snow cover }\left(\mathrm{mm} \mathrm{H}_{2} \mathrm{O}\right)\end{array}$ & $0-500$ & No \\
\hline SNO50COV & $\begin{array}{l}\text { Fraction of } \\
\text { SNOCOVMX that } \\
\text { corresponds to } 100 \% \\
\text { snow cover }\end{array}$ & $0-1$ & No \\
\hline
\end{tabular}
hydrology were changed with a certain range in order to determine model sensitivity in simulations. The ranges for these parameters are listed in Table 1.
Table 1. Summary of the sensitivity analysis on the seven snowmelt parameters.

In this paper, Both SMFMX and SMFMN varied from 0 to $20 \mathrm{~mm} \mathrm{H}_{2} \mathrm{O}^{\circ} \mathrm{C}^{-1} \cdot \mathrm{d}^{-1}$, SMTMP and SFTMP from -20 to $20^{\circ} \mathrm{C}$, TIMP and SNO50COV from 0 to 1 , and SNOCOVMX from 0 to $500 \mathrm{~mm} \mathrm{H}_{2} \mathrm{O}$. These ranges were suggested by the SWAT-CUP software, and considered to be typical ranges for these parameters in the Liao source area. The ranges were divided into 10 increments, and each incremental value was then tested. When one parameter was varied, the others were fixed at the mean values of the corresponding ranges. For example, when the SMFMX was varied from 0 to $20 \mathrm{~mm} \mathrm{H}_{2} \mathrm{O}^{\circ} \mathrm{C}^{-1} \cdot \mathrm{d}^{-1}$, with an incremental value of $2 \mathrm{~mm} \mathrm{H}_{2} \mathrm{O}^{\circ}{ }^{2} \mathrm{C}^{-1} \cdot \mathrm{d}^{-1}$, the SFTMP, SMTMP, SMFMN, TIMP, SNOCOVMX, and SNO50COV parameters were held at values of $2.8^{\circ} \mathrm{C}$, $9.09^{\circ} \mathrm{C}, 9.93 \mathrm{~mm} \mathrm{H}_{2} \mathrm{O}^{\circ} \mathrm{C}^{-1} \cdot \mathrm{d}^{-1}, 0.64,20 \mathrm{~mm} \mathrm{H}_{2} \mathrm{O}$, and 0.2 , respectively. Because these parameters are independent of the stream flows generated from rainfall runoff, the sensitivity was examined in terms of the simulated versus observed stream flows in spring of the evaluation years. The values for $\mathrm{R}^{2}$ and NS were computed for the increments. In this study, a parameter was empirically considered sensitive if its variation resulted in a change in $\mathrm{R}^{2}$ and NS of more than zero.

According to the above method, the curve of the relationship between snowmelt parameters and statistical index $\mathrm{R}^{2}$ and NS is shown in Fig. 2. It can be seen that the same parameters in two watersheds have different influence on the simulation results, but in terms of sensitivity, the performance of the same parameters in two watersheds is consistent.

It can be seen in Figs 2 a) and b) that SMFMX and SMFMN are related to the snowmelt rate, so any increase 

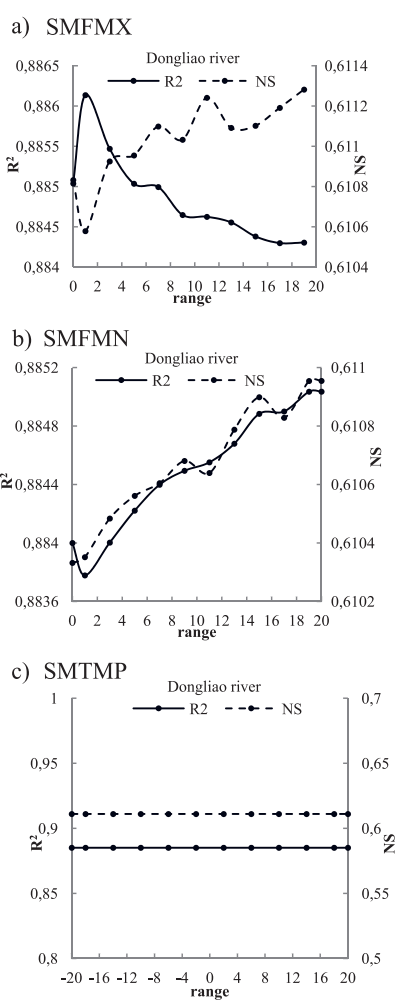

d) SFTMP
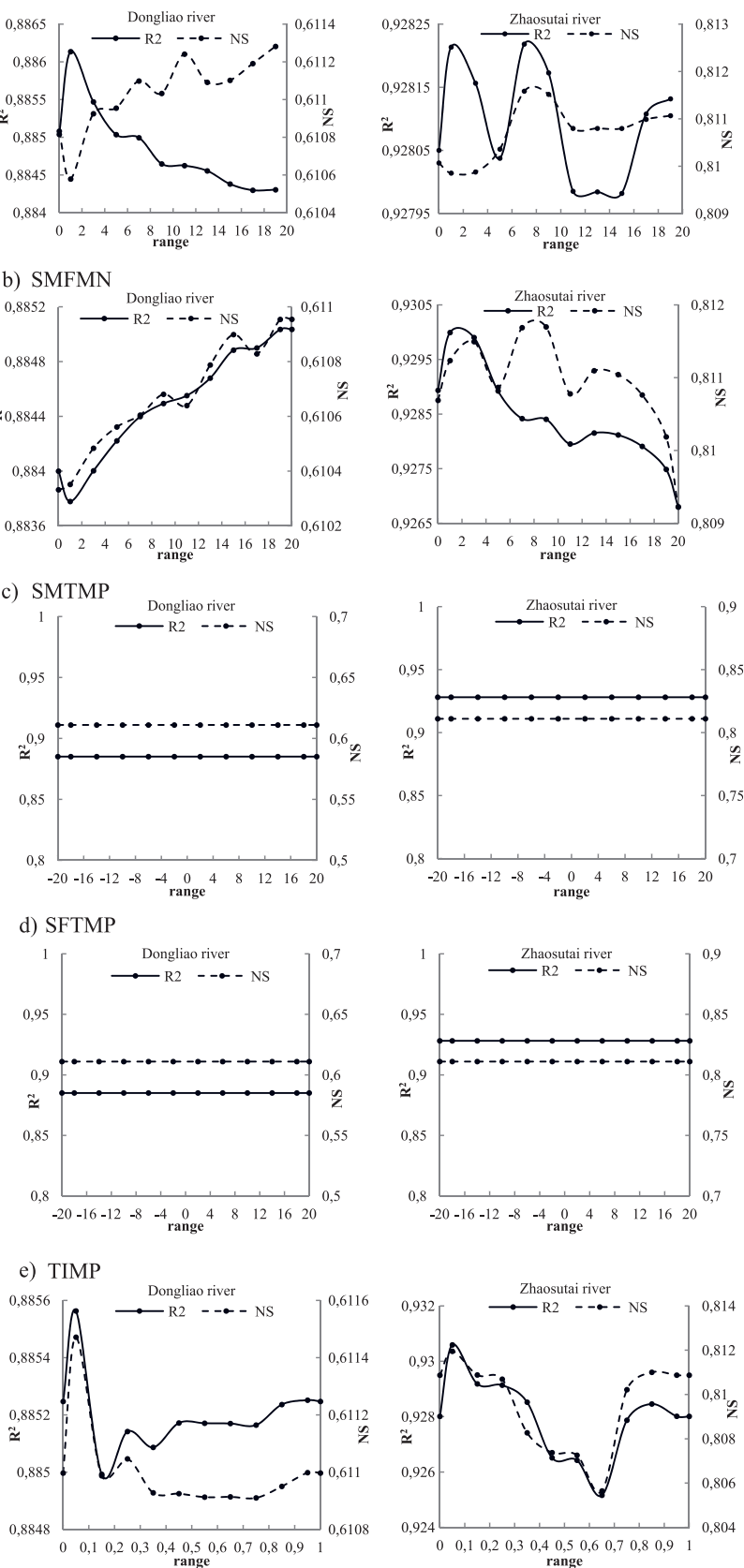

f) SNOCOVMX
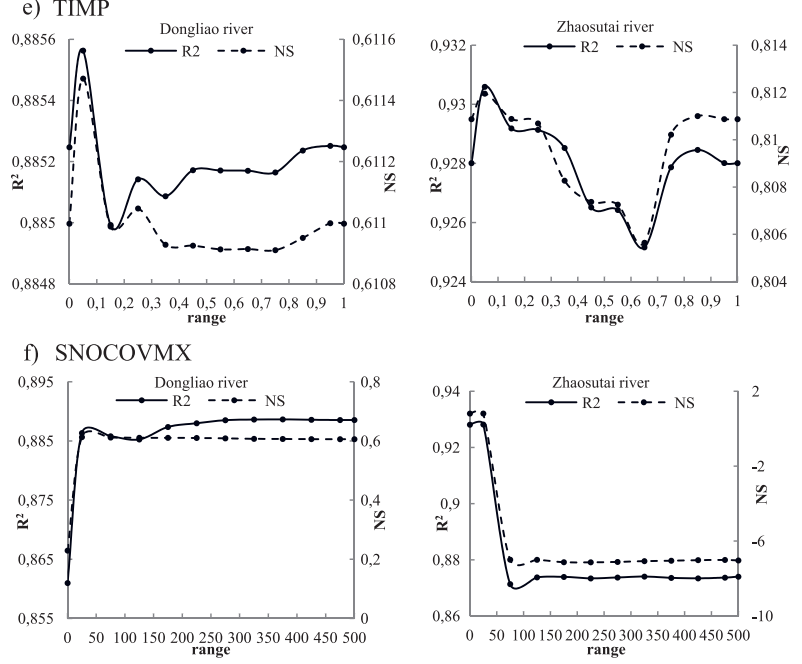

g) $\mathrm{SNO50COV}$

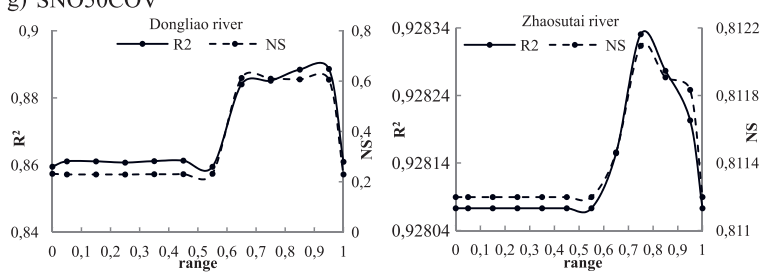

Fig. 2. Plot showing $\mathrm{R}^{2}$ and $\mathrm{NS}$ versus increments in the snowmelt parameters. in its value may result in a bigger melt factor and thus a higher melting rate. In equation 4 (snowmelt factor similar $\sin$ equation), the term $\sin [2 \pi / 365$ (i-81)] varies between $[-1,1]$ from 1 January to 31 December. A large positive value for this term means a larger influence of SMFMX on the melt factor, while a large negative value means a smaller influence of SMFMX. For the study watershed, the major snowmelt occurred from late March to May in spring, and during this period this term had a value between -0.32 and 0.92 , and negative value only appears in March. Thus the SMFMX parameter exerts a greater influence on the melt factor and is sensitive for the simulation. In the same, the influence of SMFMN, the minimum snowmelt factor, is greater if this term is positive, but smaller than SMFMX (such as the Dongliao River). SMFMN has less influence than SMFMX, although SMFMN is also a sensitive parameter.

Figs 2 c), d), and e) show that SMTMP and SFTMP didn't affect the simulation results. Theoretically, SMTMP defines when a snowpack starts or stops melting, thus affecting the snowpack amount available for melting on a specific day. As a result, the simulated stream flow hydrograph, in terms of its silhouette and peak, is influenced by variations in SMTMP. The SFTMP has a close relationship with snowpack accumulation (particularly in winter) because it is used within SWAT to classify precipitation as rain or snow. In equation 5 , the simulation is also expected to be sensitive to variations in TIMP (the snowpack temperature lag factor), which influences prediction of the snowpack temperature on a given day. In conjunction with SMTMP, the predicted snowpack temperature also defines when the snowpack starts or stops melting, and thus affects the snowpack amount available for melting on that day. As a result, SMFMX, SMTMP, and TIMP were sensitive parameters for the simulation.

The snowpack within the study watershed mainly accumulates as a result of snowfall throughout winter and in early spring. Over this period, only a small amount of the snowpack was lost to sublimation and sporadic melting. As mentioned in equation 2 , the areal depletion curve affects snowmelt only when the snowpack water content $\left(\mathrm{SNO}_{i}\right)$ is between 0 and SNOCOVMX. When $\mathrm{SNO}_{i}$ is bigger than SNOCOVMX, snow cover area is a constant value. From Fig. 2 f), the index curve mutation happens when SNOCOVMX is $25 \mathrm{~mm}$, and the index curve is constant when SNOCOVMX is more than $25 \mathrm{~mm}$. Through a review of the literature, $\mathrm{SNO}_{i}$ is far from $25 \mathrm{~mm}$ in the study area at snowmelt period, so SNOCOVMX didn't affect the simulation. Likewise, in addition to the individual points, SNO50COV and the index curve are at the state level in a longer period. Thus, variations of SNOCOVMX and SNO50COV were not sensitive for the simulation in this study.

\section{Snowmelt Parameters Range Determination}

After the sensitivity analysis of the snowmelt parameters, five snowmelt parameters (SFTMP, SMTMP, 
Table 2. The optimum value range of snowmelt parameters for Dongliao river watershed.

\begin{tabular}{|c|c|c|c|c|c|}
\hline \multirow{2}{*}{ Parameters } & \multicolumn{4}{|c|}{ Dongliao river watershed } & \multirow[b]{2}{*}{ Change $\left(\mathrm{R}^{2}\right)$} \\
\hline & The best range & Maximum(NS) & Change(NS) & $\operatorname{Maximum}\left(\mathrm{R}^{2}\right)$ & \\
\hline SMFMX & $18 \sim 20$ & 0.6113 & $0.1180 \%$ & 0.8861 & $0.2119 \%$ \\
\hline SMFMN & $18 \sim 20$ & 0.6110 & $0.1020 \%$ & 0.8850 & $0.1422 \%$ \\
\hline SMTMP & 1 & 0.6110 & $0.0000 \%$ & 0.8851 & $0.0000 \%$ \\
\hline SFTMP & 1 & 0.6110 & $0.0000 \%$ & 0.8850 & $0.0000 \%$ \\
\hline TIMP & $0 \sim 0.1$ & 0.6115 & $0.0919 \%$ & 0.8856 & $0.0645 \%$ \\
\hline
\end{tabular}

Table 3. The optimum value range of snowmelt parameters for Zhaosutai river watershed.

\begin{tabular}{|c|c|c|c|c|c|}
\hline \multirow{2}{*}{ Parameters } & \multicolumn{4}{|c|}{ Zhaosutai river watershed } & \multirow[b]{2}{*}{ Change $\left(\mathrm{R}^{2}\right)$} \\
\hline & The best range & Maximum(NS) & Change(NS) & $\operatorname{Maximum}\left(\mathrm{R}^{2}\right)$ & \\
\hline SMFMX & $6 \sim 8$ & 0.8116 & $0.2136 \%$ & 0.9282 & $0.0255 \%$ \\
\hline SMFMN & $6 \sim 8$ & 0.8117 & $0.3055 \%$ & 0.9300 & $0.3448 \%$ \\
\hline SMTMP & 1 & 0.8110 & $0.0000 \%$ & 0.9281 & $0.0000 \%$ \\
\hline SFTMP & 1 & 0.8110 & $0.0000 \%$ & 0.9281 & $0.0000 \%$ \\
\hline TIMP & $0 \sim 0.1$ & 0.8119 & $0.7830 \%$ & 0.9306 & $0.5872 \%$ \\
\hline
\end{tabular}

SMFMX, SMFMN, and TIMP) were considered sensitive and taken as calibration parameters while SNOCOVMX and SNO50COV were considered insensitive. According to the maximum values of $\mathrm{R}^{2}$ and NS, the most suitable parameters were determined in two watersheds. Fig. 2 illustrates that $\mathrm{R}^{2}$ is basically consistent with NS of other parameters except SMFMX, with a maximum of two statistical indexes corresponding to the same of the most suitable parameters. $\mathrm{R}^{2}$ of SMFMX is fluctuations in nearby 0.9 , and simulation results were good, so only consider the NS curve when determining the most suitable parameter range. Tables 2 and 3 are the optimum value range of snowmelt parameters for the Dongliao Zhaosutai river watersheds, respectively.

\section{Results and Discussion}

\section{Model Calibration and Validation}

The SWAT model was calibrated by determining the set of model snowmelt parameters that achieved the best goodness-of-fit between observed and predicted values. In this study, the Nash-Sutcliffe efficiency coefficient (NS) and the correlation coefficient $\left(\mathrm{R}^{2}\right)$ were used to evaluate the goodness-of-fit of the SWAT model performance. It was considered that when $\mathrm{R}^{2} \geq 0.6$ and $\mathrm{NS} \geq 0.5$, then the model simulation results are reliable and could be used for simulation.

A SWAT model was established for the three small watersheds in the Liao source area plus the Dongliao, Zhaosutai, and Tiaozi river watersheds. Due to the lack of the observed flow data in the Tiaozi, only the Quantai gauging station (on the Dongliao River) and the Lishu gauging station (on the Zhaosutai River) were selected to calibrate and validate the model. The calibration period was 2006-08, while the verification period was 2009-10. A comparison of the measured and predicted monthly average daily flows for the calibration period and the validation period are shown in Figs 3 and 4, respectively.

During the calibration period, the $\mathrm{R}^{2}$ and NS coefficient values at Quantai Station were 0.82 and 0.79 , respectively, while the $\mathrm{R}^{2}$ and NS coefficient values at the Lishu station were 0.81 and 0.77 , respectively. During the validation period, the $\mathrm{R}^{2}$ and NS coefficient values at Quantai were 0.82 and 0.78 , respectively, while the $\mathrm{R}^{2}$ and NS coefficient

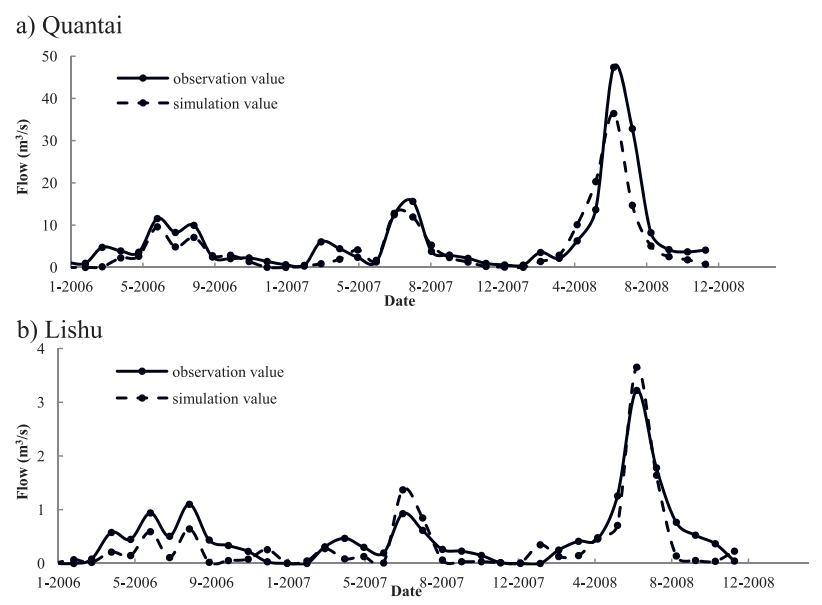

Fig. 3. Comparison of the measured and predicted monthly average daily flows at Quantai station and Lishu station during the calibration period (2006-2008). 
a) Quantai

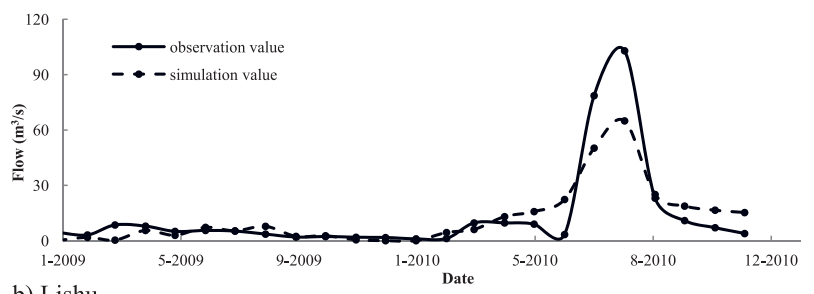

b) Lishu

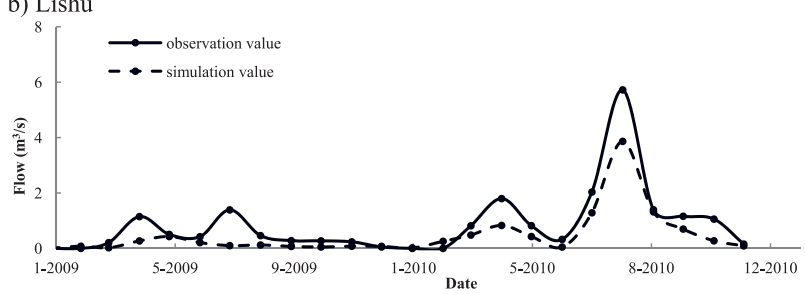

Fig. 4. Comparison of the observed and predicted monthly average daily flows at Quantai station and Lishu station during the verification period (2009-2010).

values at Lishu station were 0.79 and 0.73 , respectively. Based on the adopted evaluation criteria it was considered that the level of accuracy of the predicted monthly average daily flows were acceptable.

The only sediment data recorded during the calibration and validation periods was collected at Quantai. Fig. 5 shows a comparison of the measured and predicted monthly total sediment discharge in tons for the calibration period and the validation period.

During the calibration period the $\mathrm{R}^{2}$ and NS coefficient values for monthly total sediment discharge at Quantai were 0.83 and 0.79 , respectively, while the $\mathrm{R}^{2}$ and NS coefficient values at Quantai during the validation period were 0.80 and 0.75 , respectively. The predicted results are satisfactory given the level of accuracy of the predicted monthly total sediment discharge.

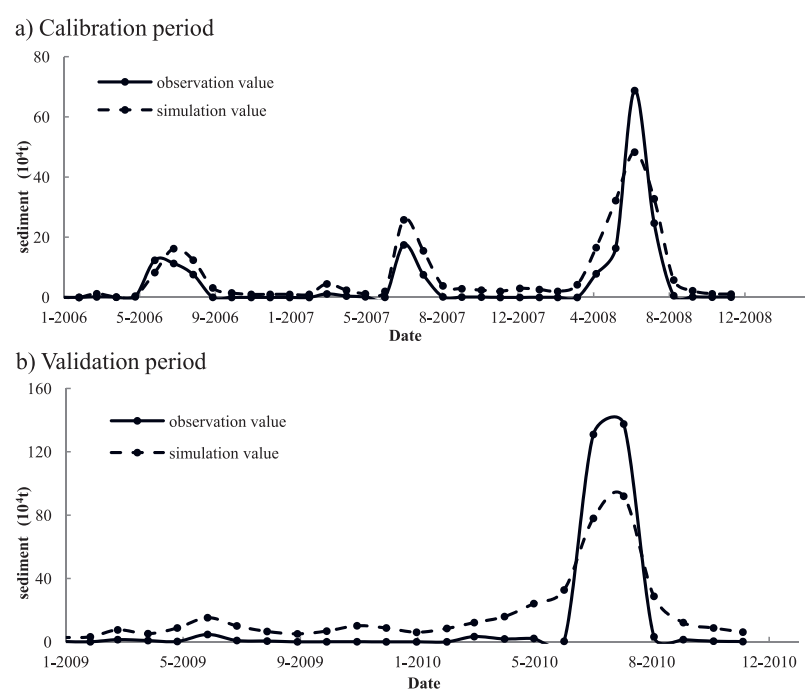

Fig. 5. Comparison of the measured and predicted monthly total sediment discharge at Quantai station during the calibration and verification period.

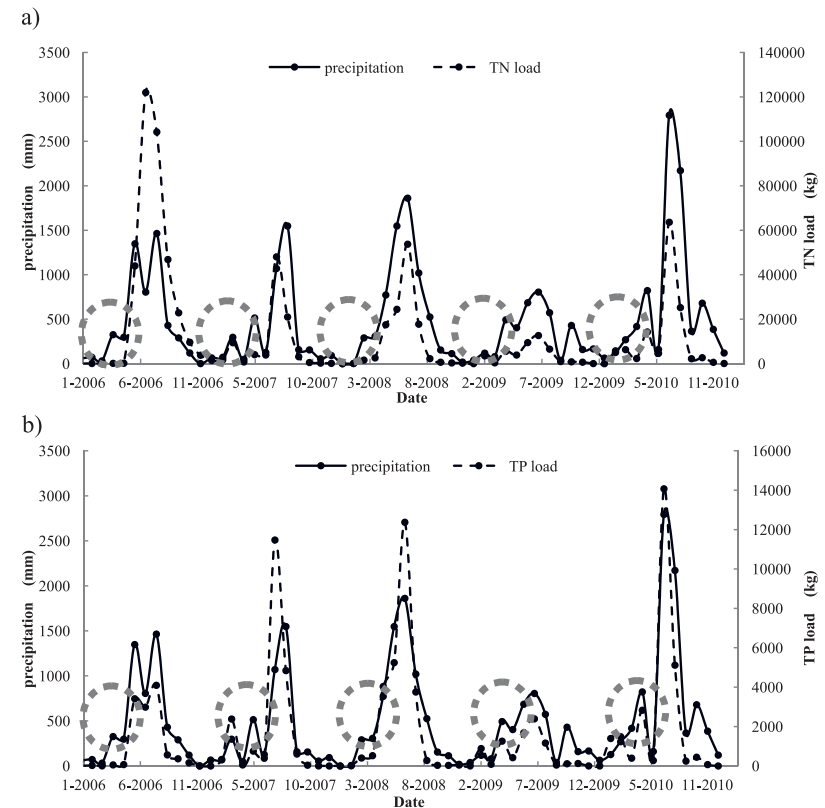

Fig. 6. The curve of precipitation and TN, TP load from 2006 to 2010 .

\section{The Simulation Results of Nonpoint Source Pollution for Spring Snowmelt}

Our paper is based on the calibration and validation of the SWAT model with the snowmelt module, and analysis of the exports rule of nonpoint source pollution for the spring snowmelt period on the scale of 2006-10 in the Liao source area.

In Fig. 6, the exports of TN, TP and the precipitation in the study area have almost the same change trend. In July and August every year as the precipitation increases, pollutant load peak appeared. In addition, each year in

Table 4 The data of TN and TP seasonal exports from the Liao River source area for the period 2006-2010.

\begin{tabular}{|c|c|c|c|c|c|}
\hline Output & Year & Winter & Spring & Summer & Fall \\
\hline \multirow{7}{*}{ TN(kg) } & 2006 & 134 & 437 & 270306 & 4469 \\
\cline { 2 - 6 } & 2007 & 7101 & 14382 & 73079 & 4032 \\
\cline { 2 - 6 } & 2008 & 395 & 21843 & 96047 & 3378 \\
\cline { 2 - 6 } & 2009 & 3902 & 9945 & 28816 & 2572 \\
\cline { 2 - 6 } & 2010 & 5959 & 23011 & 93560 & 5623 \\
\cline { 2 - 6 } & average & 3498 & 13924 & 112361 & 4015 \\
\hline \multirow{5}{*}{ TP(kg) } & 2006 & 29 & 136 & 10501 & 1094 \\
\cline { 2 - 6 } & 2007 & 315 & 3196 & 16714 & 655 \\
\cline { 2 - 6 } & 2008 & 30 & 4968 & 21383 & 349 \\
\cline { 2 - 6 } & 2009 & 939 & 1774 & 5246 & 292 \\
\cline { 2 - 6 } & 2010 & 1405 & 4718 & 19474 & 767 \\
\cline { 2 - 6 } & average & 544 & 2958 & 14664 & 632 \\
\hline
\end{tabular}




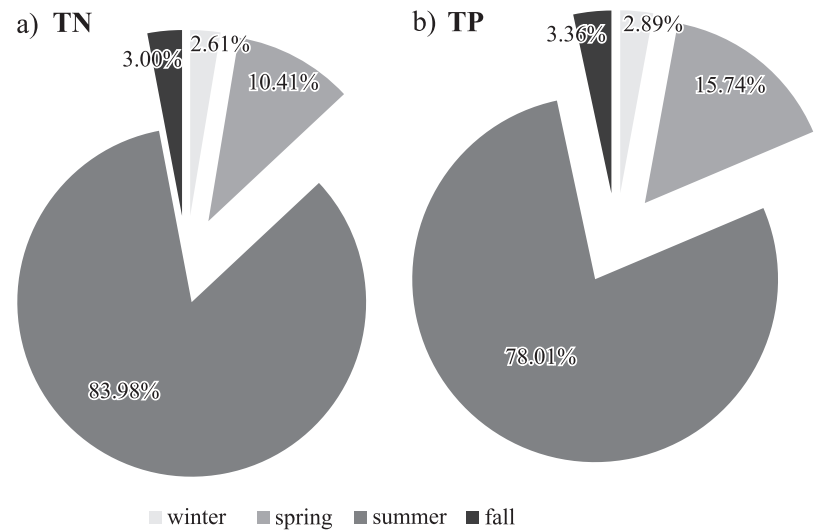

Fig. 7. The average proportion of TN and TP seasonal exports from the Liao River source area for the period 2006-2010.

March to May (dotted circled), the exports of TN and TP concentration also has a small rise, and there is a small peak. In order to explain the reason for this phenomenon, the paper gives exports data of nonpoint source pollution in season as well as the proportion in each season, which is shown in Table 4 and Fig. 7.

Table 4 and Fig. 7 shows that the exports of nonpoint source nitrogen and phosphorus mainly concentrated in summer, the proportion of TN and TP from June to September was $83.98 \%$ and $78.01 \%$, respectively. In summer, a lot of nitrogen and phosphorus were accumulated in soil surface with intensive agricultural activities and chemical fertilizer, which will cause pollution under the scouring effect of precipitation and irrigation. It can be seen that nitrogen and phosphorus loads increase with precipitation, this is due to the increase of surface runoff, resulting in the ability to enhance the transport of pollutants. In other words, precipitation is the main driving force of pollutants into the river in summer.

In addition, the exports of nonpoint source nitrogen and phosphorus appear small peak in spring (March to May). In this period, the proportion of $\mathrm{TN}$ and $\mathrm{TP}$ was $10.41 \%$ and $15.74 \%$, respectively. It can be seen that the loss of pollutants is more serious for spring snow melting period in the source area of Liao River. This is because the study area has a long frozen period in winter each year, mineralization function of nitrogen and phosphorus can be accelerated in the process, resulting in a large number of nitrogen and phosphorus retention in the soil. In spring, an accumulation of nonpoint source pollutants in the soil flush into the river in a short time, with the freezethawing process and spring scouring action. By the way, the loss of vegetation in spring can further exacerbate the phenomenon.

Due to unevenly distribution of annual precipitation and phenomenon of spring scouring action is serious, resulting in a large number of nonpoint source pollutants concentrated outflow. It is characteristic of suddenness and accumulation. Therefore, seasonal rainfall and snowmelt are main driving forces of the agricultural nonpoint source pollution in the study area, and summer and spring are high-risk seasons which occurs pollution of nonpoint source. The research got the same results with the literature [23]. However, Wang proposed that the model had an overall better performance for evaluation years with a larger snowpack than for those with a smaller snowpack. We will prove the point in the future.

\section{Conclusions}

In this paper the nonpoint source pollution load model considering the snowmelt module was established based on SWAT in the Liao source area. The sensitivity analysis of snowmelt parameters aims to determine the optimal range of parameters, and to explore the role of snowmelt in the simulation. Analyzing the output rules and the reasons for nonpoint source pollution in the spring snowmelt period leads to several findings in the study area:

1. The sensitivity analysis indicated that of the seven snowmelt parameters, five - namely SFTMP, SMTMP, SMFMX, SMFMN, and TIMP - were sensitive for the simulation, while SNOCOVMX and SNO50COV were considered to be insensitive. Subsequently, the optimal range for these snowmelt parameters were determined to further refine the model, and improved the accuracy of the SWAT model for the snowmelt process. It provided a new suitable method for the nonpoint source pollution simulation in the cold regions.

2. The SWAT model was established for three small watersheds in the Liao source area: the Dongliao, Zhaosutai, and Tiaozi river basins. The evaluation indicated that the SWAT model considering the snowmelt module had good performance for both the calibration and verification periods. It showed that the model could well simulate the nonpoint source pollution process in a cold area, and developed the potential in other similar regions.

3. The simulation results showed that the change tendency of nonpoint source pollution and precipitation were consistent. It had the characteristic of suddenness and accumulation with the phenomenon of spring scouring action. Therefore, rainfall and snowmelt was the main driver of nonpoint source pollution, and summer and spring were the high-risk seasons.

Due to the complexity principle and parameters of the SWAT snowmelt module, the model has many uncertainty factors. Observation and test methods cannot completely satisfy distributed snowmelt model research based on physical processes nowadays, but as conditions improve, further study of the snowmelt physical process and its modeling will be performed to consider other uncertainty factors.

\section{Acknowledgements}

This research was financially supported by the Department of Science and Technology of Jilin Province 
and the National Key S\&T Special Project of Control and Management of the Water Pollution under the agreement 2012ZX07202-00. The financial supported by Graduate Innovation Fund of Jilin University, Scientific Research Foundation for Returned Scholars of Jilin University and the Seed Science Foundation of the Ministry of Education of China are also greatly appreciated.

\section{References}

1. YANG Y.H., YAN B.X., SHEN X.B. Assessment of point and nonpoint sources pollution in Songhua River basin, northeast China by using revised water quality model. Chines. Geogr. SCI. 20 (1), 30, 2010.

2. LINDAU C., BOLLICH P., BOND J. Soybean best management practices for Louisiana, USA, agricultural nonpoint source water pollution control. Commun. Soil. Sci. Plan. 41 (13), 1615, 2010.

3. ZHANG L., LU W. X., AN Y. L., LI D., GONG L. Evaluation of non-point source pollution reduction by applying best management practices in Dongliao River watershed using SWAT Model. Fresen. Environ. Bull. 22 (2A), 531, 2013.

4. LI J.K., DU J., LI H. E., LI Y. J., LIU Z.C. A SWAT modelbased simulation of the effects of non-point source pollution control measures on a river basin. Pol. J. Environ. Stud. 24 (3), 1133, 2015.

5. FU Y.C., RUAN B.Q., GAO T. Watershed agricultural nonpoint source pollution management. Pol. J. Environ. Stud. 22 (2), 367, 2013.

6. XIA J., ZHAI X.Y., ZHANG Y.Y. Progress in the research of water environmental nonpoint source pollution models. Progress in Geography. 31 (7), 941, 2012 [In Chinese].

7. MAO Y.N., YEA Z., WANG X.L., ZHANG Y.Y. Nonpoint source pollution models base on GIS and RS: A review. Journal of BeiJing Normal University (Natural Science). 49 (4), 407, 2013 [In Chinese].

8. ARNOLD J.G., ALLEN P.M., BERNHARDT G. A comprehensive surface-groundwater flow model. J. Hydrol. 142, 47, 1993.

9. LIU R.M., ZHANG P.P., WANG X.J., WANG J.W., YU W.W., SHEN Z.Y. Cost-effectiveness and cost-benefit analysis of BMPs in controlling agricultural nonpoint source pollution in China based on the SWAT model. Environ. Monit. Assess. 186 (12), 9011, 2014.

10. QU J.H., ZHOU J., REN K. Identification of nonpoint source of pollution with nitrogen based on soil and water assessment tool in Qinhuangdao city, China. Environ. Eng. Manag. J. 14
(8), 1887, 2015.

11. KIM S.B., SHIN H.J., PARK M., KIM S.J. Assessment of future climate change impacts on snowmelt and stream water quality for a mountainous high-elevation watershed using SWAT. Paddy. Water. Environ. 13, 557, 2015.

12. HAO Z.C., ZHANG Y.G., YANG C.G., LI J. W., DA W.D.Z. Effects of topography and snowmelt on hydrologic simulation in the Yellow River ss source region. Advances in water science. 24 (3), 311, 2013 [In Chinese].

13. KACZOR G., BUGAJSKI P. Impact of Snowmelt Inflow on Temperature of Sewage Discharged to Treatment Plants. Pol. J. Environ. Stud. 21 (2), 381, 2012.

14. PETERSON J.R., HAMLETT J.M. Hydrologic calibration of the SWAT model in a watershed containing frangipani soils. Am. Water. Res. Assoc. 34 (3), 531, 1998.

15. FONTAINE T.A., CRUICKSHANK T.S., ARNOLD J.G., HOTCHKISS R.H. Development of a snowfall-snowmelt routine for mountainous terrain for the soil water assessment tool (SWAT). Hydrogeol. J. 262, 209, 2002.

16. WANG T.M., WANG Y.Y., LIU Y.P., XIANG B., MA G.W., HU Y. Study and application of estimation method for spring non-point source pollution in northeast China. Journal of Agro-Environment Science. 31 (4), 807, 2012 [In Chinese].

17. LV C., LIU D.M., LIU T. Load estimation of agricultural non-point source pollution in source area of Liao River. Journal of Water Resources \& Water Engineering. 24 (6), 185, 2013 [In Chinese].

18. ZHAO J. Simulation research for export of agricultural nonpoint source nitrogen and phosphorus and its risk assessment in the source area of Liao River. Jilin University. 2014 [In Chinese].

19. BIAN J.M., HU Y.X., LI Y.S., MA Y.X., BIAN J. Water quality assessment in source area of Liao River based on BP neural network. Research of Soil and Water Conservation. 21 (1), 147, 2014 [In Chinese].

20. MENG X.Y., JI X.N., LIU Z.H., XIAO J.C., CHEN X., WANG F. Research on improvement and application of snowmelt module in SWAT. Journal of Natural Resources. 29 (3), 528, 2014 [In Chinese].

21. ETIENNE L., FRANCOIS A., ANN V.G. Evaluation of stream flow simulation by SWAT model for two small watersheds under snowmelt and rainfall. Hydrolog. Sci. J. 53 (5), 961, 2008.

22. MAGALI T., DANIEL C. Evaluating the SWAT's snow hydrology over a Northern Quebec watershed. Hydrol. Process. 28, 1858, 2014.

23. WANG X., MELESSE A.M. Evaluation of the SWAT model's snowmelt hydrology in a Northwestern Minnesota Watershed. T. ASABE. 48 (4), 16, 2005. 